\title{
Experimental study of polymerization and crystallization kinetics of polyamide 6 obtained by anionic ring opening polymerization of $\varepsilon$-caprolactam
}

\author{
Céline Vicard, Olivier De Almeida*, Arthur Cantarel, Gérard Bernhart ${ }^{1}$ \\ Institut Clément Ader (ICA), Université de Toulouse, CNRS, Mines Albi, UPS, INSA, ISAE-SUPAERO, Campus Jarlard, 81013 Albi CT Cedex 09, France
}

Keywords:

Liquid reactive polyamide 6 composite Polymerization/crystallization coupling In situ synthesis via DSC

\begin{abstract}
To adapt liquid reactive processes to thermoplastic composite manufacturing, synthesis kinetics of PA6 from $\varepsilon$-caprolactam monomer have been investigated. This reaction involves simultaneously polymerization of monomers and crystallization of growing chains. It has been studied by DSC over a wide range of isothermal and non-isothermal conditions, and TGA, DSC and WAXS experiments were performed on polymerized samples. Shape of DSC curves allowed to identify the degree of interaction between polymerization and crystallization. At high temperature or high heating rate, polymerization occurs first and crystallization is delayed because of the low supercooling. When phenomena are fully decoupled, the final properties are close to conventional PA6. For lower conditions, crystallization depends on the availability of chains and polymerization controls the synthesis time. The high mobility of the environment favors the final degree of conversion and the properties of the crystalline phase. At very low temperature, a two-step crystallization is observed, due to a critical molecular weight that is required for nucleation and the degree of conversion could be affected by entrapment of reactive species in crystals.
\end{abstract}

\section{Introduction}

Long fiber reinforced thermoplastic composites offer an interesting compromise between mechanical performances, chemical resistance and recyclability that make them serious challengers of thermoset composites [1]. However, the high melting temperature and viscosity of thermoplastic matrices still restrict their growth mainly because of the expensive and time-consuming manufacturing processes like autoclave or hot press. High molar mass macromolecules exhibit at the molten state a non-Newtonian viscosity that is 100 to 1000 times higher than uncured thermosets [2]. Impregnation of reinforcing yarns is therefore necessarily a slow process although the use of complex semi-finished products (commingled, powdered) $[1,3,4]$ or fast manufacturing processes $[4,5]$ reduce the consolidation time of thermoplastic composites.

\footnotetext{
* Corresponding author

E-mail addresses: celine.vicard@mines-albi.fr (C. Vicard), olivier.dealmeida@ mines-albi.fr (O. De Almeida), arthur.cantarel@iut-tarbes.fr (A. Cantarel), gerard. bernhart@irt-saintexupery.com (G. Bernhart).

1 Present address: IRT Saint-Exupéry, 118 route de Narbonne, CS 44248, 31432 Toulouse, France.
}

To overcome these limitations, reactive systems leading to a thermoplastic polymer represent a promising alternative for thermoplastic composites fabrication. The initial low viscosity of these systems is indeed compatible with liquid molding processes (Resin Transfer Molding, Liquid Resin Infusion). Since the impregnation process and cure temperature of reactive thermoplastics and epoxy-based resins are similar [6], conventional infusion systems can be used without extensive modifications.

Like thermoset resins, the thermoplastic matrix is obtained by in situ polymerization of its low-viscosity monomer after impregnation of the fibrous structure. Processability of reactive thermoplastic systems depends on the matrix viscosity, which is driven by the polymerization kinetics $[7,8]$. The control of the reaction is thus critical for process optimization as it affects the porosity of composites [9-11] and may influence the fiber-matrix adhesion [8,12].

Among the different reactive thermoplastics, semi-crystalline polyamide 6 (PA6) is of particular interest for automotive applications as it is already massively used for semi-structural parts. Synthesis of PA6 is achieved by anionic ring-opening polymerization of its monomer $\varepsilon$-caprolactam by means of an activator and a catalyst. Their nature and concentrations in the reactive mixture strongly affect the polymerization kinetics $[13,14]$. The reactivity of 
the mixture can therefore be tuned for mass production of composite [15].

The PA6 synthesis is however particular in that both chain polymerization and polymer crystallization occur. This is due to the possible synthesis temperature range that coincides with the crystallization temperature of PA6. The consequence of these simultaneous mechanisms is a strong coupling between both phenomena: crystallization kinetics depends on the increasing amount of available polymer chains during polymerization. Crystallization may induce an early increase of the reactive mixture viscosity that could slow down the flow during infusion. On the other hand, the increase of the processing temperature slows down crystallization but accelerates the polymerization and may limit the infusion time. Understanding the coupled polymerizationcrystallization kinetics is therefore essential to optimize composite manufacturing processes and has motivated many studies in the last decades.

Characterization of PA6 synthesis has been mainly performed at a bulk scale using an adiabatic reactor [14,16-22]. This is an inverse approach that consists in monitoring the temperature of the reactive mixture at the core of an insulated reactor during polymerization and crystallization. The main advantage of this approach is that several hundred grams of polymer are synthesized which ensures the homogeneity of the reactive mixture. However, as both phenomena are exothermic, the separation of their contribution to the temperature increase can only be achieved by using complex kinetic models [22]. Another drawback of this method is that it does not allow for isothermal synthesis, the thermo-dependence of phenomena is thus difficult to characterize.

On the other hand, Differential Scanning Calorimetry (DSC) is an interesting method to follow the in situ synthesis at a smaller scale. First studies have mainly been focused on the influence of the nature and concentration of catalysts on reaction kinetics [13,23-26]. Syntheses were performed under a few representative conditions in order to highlight the coupling or separation of polymerization and crystallization. PA6 reactive mixtures have only recently been investigated over a wide range of isothermal and non-isothermal conditions using DSC by Khodabakhshi et al. [27]. However, the focus was on mixtures designed for inkjet printing involving a very high concentration of catalysts for a rapid reaction. Thus kinetic data on reactive mixtures dedicated to composite manufacturing are still lacking.

This study investigates the coupled polymerizationcrystallization of PA6 from $\varepsilon$-caprolactam under isothermal and non-isothermal conditions using DSC. The reactive mixture was selected to obtain a polymerization kinetic that suits with liquid molding processes. The final monomer conversion was determined by TGA based on evaporation of residual monomer after polymerization. DSC and WAXS were used to characterize the degree of crystallinity and microstructure of synthesized semi-crystalline PA6.

\section{Experimental}

\subsection{Materials}

All reactants have been kindly supplied by Brüggemann Chemical, Germany. The products used for the anionic ring opening polymerization of PA6 are the $\varepsilon$-caprolactam monomer "APNYLON $^{\mathbb{R}}$, caprolactam magnesium bromide as catalyst $(\mathrm{MgBrCL}-$ "Nyrim $\mathrm{C}^{\circledR}{ }^{\circledR} 1.4 \mathrm{~mol} \mathrm{~kg}^{-1}$ in caprolactam) and bifunctional hexamethylene-1,6-dicarbamoylcaprolactam as activator (HDCL "Brüggolen C20P ${ }^{\circledR}$ " $2.0 \mathrm{~mol} \mathrm{~kg}^{-1}$ in caprolactam). Since the reaction is sensitive to moisture [28], products were dried overnight at $308 \mathrm{~K}$ under vacuum prior to mixture preparation and all subsequent handling was performed in an inert atmosphere to prevent any moisture uptake.

The reactive mixture was prepared by melting reactants under stirring. The ratio $\mathrm{MgBrCL} / \mathrm{HDCL}$ used was $0.79 / 1.10 \mathrm{~mol}$ \% of CL. Once homogeneous, batch was quenched in liquid nitrogen to prevent early reaction. The product was then stored in a sealed pot at $255 \mathrm{~K}$ before sampling.

\subsection{Analysis methods}

\subsubsection{DSC - kinetics characterization}

Physical and chemical phenomena were monitored using a power-compensated Perkin-Elmer 8500 Differential Scanning Calorimeter (DSC) under nitrogen. DSC samples were prepared with 9-12 mg of reactive mixture. This relatively high sample mass for DSC analyses allows a reasonable compromise between heat transfer inertia and sampling heterogeneity. The mixture was sealed in hermetic aluminum pans under inert atmosphere to prevent monomer evaporation and moisture uptake. This procedure differs from Khodabakhshi et al. [27] who achieved DSC tests with open pans without lids to reproduce the conditions of inkjet printing. The inherent evaporation of monomer, which starts around $373 \mathrm{~K}$, is superimposed on the polymerization and crystallization and causes a mass loss of $20 \mathrm{wt} \%$ in average.

The reaction kinetics were characterized under isothermal and non-isothermal conditions. Isothermal PA6 syntheses were achieved by heating a sample at $300 \mathrm{~K} \mathrm{~min}^{-1}$ from $273 \mathrm{~K}$ to an isotherm temperature $T_{i s o}$ ranging from 403 to $473 \mathrm{~K}$. The sample was kept at $T_{\text {iso }}$ until the conversion of $\varepsilon$-caprolactam into PA6 is achieved and then cooled at $-10 \mathrm{~K} \mathrm{~min}^{-1}$ to $273 \mathrm{~K}$. Non-isothermal cycles consisted in heating the mixture at different rates $(0.5,1,2,5$ and $10 \mathrm{~K} \mathrm{~min}^{-1}$ ) from 273 to $523 \mathrm{~K}$. To ensure repeatability, 4 samples were tested for each synthesis condition except at $0.5 \mathrm{~K} \mathrm{~min}^{-1}$ for which 2 tests were performed.

\subsubsection{DSC - crystallinity characterization}

For each isothermal synthesis, one out of the four samples underwent a subsequent heating DSC scan at $10 \mathrm{~K} \mathrm{~min}^{-1}$ from $273 \mathrm{~K}$ to $523 \mathrm{~K}$ in order to assess the enthalpy of fusion and melting temperature of the crystalline phase. For the non-isothermal synthesized samples, the properties of the crystalline phase were determined directly on the synthesis curves obtained at different heating rates.

\subsubsection{WAXS - crystalline structure}

Wide-Angle X-ray Scattering (WAXS) was used to analyze the crystalline structure formed during the synthesis of PA6. WAXS measurements were conducted on the two other isothermally synthetized samples after removing them from the DSC pans. The experiments were performed in reflected radiation mode by means of a Philipps Panatical X'Pert PRO Diffractometer using a $\mathrm{Cu} \mathrm{K} \alpha$ radiation $(\lambda=1.54 \AA)$. Data were collected over a scattering angle of $2 \theta=5^{\circ}-35^{\circ}$ with increments of $0.05^{\circ}$.

\subsubsection{TGA - monomer conversion}

Final monomer conversion was determined by Thermogravimetric Analysis (TGA) $[29,30]$ by means of a coupled Setaram TGADSC 111 under nitrogen. Two samples of each synthesis condition were tested with a heating rate of $5 \mathrm{~K} \mathrm{~min}^{-1}$ from room temperature to $773 \mathrm{~K}$. It should be noticed that isothermally synthetized samples used in TGA are the same than for WAXS analysis, i.e. these samples did not undergo a subsequent heating ramp at $10 \mathrm{~K} \mathrm{~min}^{-1}$. Prior to analysis, samples were stored in a desiccator to prevent moisture uptake. However, the samples may have absorbed water during WAXS experiment or during their transfer into TGA 
crucibles that could not be achieved in anhydrous environment.

\section{Results and discussion}

\subsection{Non-isothermal syntheses}

Representative DSC curves of non-isothermal syntheses of PA6 are presented in Fig. 1. Fig. 1a shows the first part of the heating stage between 323 and $353 \mathrm{~K}$. The double endothermic peaks correspond to the fusion of the products in the reactive mixture: a first small peak around $327-330 \mathrm{~K}$ due to catalysts is followed by a main peak around $341-346 \mathrm{~K}$ due to the $\varepsilon$-caprolactam. A thermal lag is observed when increasing the heating rate.

Fig. $1 \mathrm{~b}$ focuses on the temperature range of PA6 syntheses. It results in one or two exothermic peaks and, depending on the heating rate, an additional endothermic peak. For clarity maximum peak temperatures of phenomena are plotted versus the heating rate in Fig. 2.

As displayed in Fig. 2 the exothermic peaks shift towards higher temperatures (from 429 to $467 \mathrm{~K}$ ) when increasing the heating rate. Moreover, the logarithmic scale suggests an exponential influence of the heating rate on the reaction temperature.

The exothermic peaks in Fig. 2 correspond to PA6 polymerization and crystallization. The double peak obtained for $\dot{T}=5 \mathrm{~K} \mathrm{~min}^{-1}$ shows the occurrence of both phenomena during the heating ramp. Polymerization is the first process to occur, as short chains cannot crystallize in the reaction temperature range. The first maximum on DSC curve then corresponds to polymerization and the second one to polymer crystallization. The separation of the two transformations at high temperature is due to a slow crystallization kinetic because of the low supercooling.

Low heating rates, i.e. $0.5,1$ and $2 \mathrm{~K} \mathrm{~min}^{-1}$, result in a single exothermic peak at low temperature and an endothermic peak around $493 \mathrm{~K}$. The latter corresponds to the fusion of PA6 crystals formed during polymerization (Melting in Fig. 2). Crystallization thus occurs simultaneously during chain polymerization. The apparition of a single exothermic peak is probably due to the limitation induced by polymerization on the crystallization process, as the high supercooling involves an instantaneous crystallization of PA6 growing chains.

The curve at $\dot{T}=10 \mathrm{~K} \mathrm{~min}^{-1}$ is characterized by a unique exothermic peak that ends below the melting temperature range. As no melting is observed on DSC curves, this peak corresponds to the sole polymerization of PA6. The shift of the polymerization temperature towards high temperature induces a very low

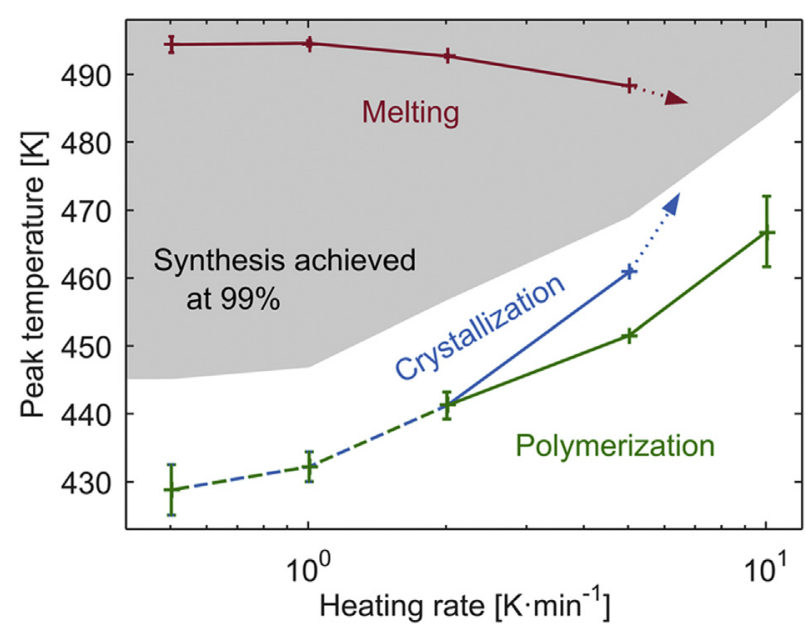

Fig. 2. Polymerization, crystallization and melting temperatures as a function of heating rate.

supercooling for crystallization. The resulting crystallization kinetics is thus so low that when reaching the melting range no crystals could be formed and the polymerized mixture remained liquid.

\subsection{Isothermal syntheses}

One representative DSC curve per isothermal temperature $T_{\text {iso }}$ (between 403 and $473 \mathrm{~K}$ every $10 \mathrm{~K}$ ) is shown on Fig. 3. It should be noticed that the melting of the reactive mixture occurs during the fast heating ramp $\left(300 \mathrm{~K} \mathrm{~min}^{-1}\right)$ and is fully achieved before the beginning of isotherm.

Shape of DSC curves changes over the investigated temperature range. Syntheses at $473 \mathrm{~K}$ lead to one sharp exothermic peak, while at $453 \mathrm{~K}$ and $463 \mathrm{~K}$ two distinct peaks are obtained. Between 423 and $443 \mathrm{~K}$, syntheses are characterized by one dissymmetric peak with a shoulder; and at $403 \mathrm{~K}$ and $413 \mathrm{~K}$ the DSC scans exhibit a double exothermic peak with a first maximum at the early stage of the reaction.

In order to understand the synthesis process, the samples were cooled from $T_{\text {iso }}$ to $273 \mathrm{~K} \mathrm{at}-10 \mathrm{~K} \mathrm{~min}^{-1}$ at the end of isotherm and then heated at $10 \mathrm{~K} \mathrm{~min}^{-1}$ until $543 \mathrm{~K}$. Representative DSC scans of the cooling phase are shown in Fig. 4 for three different $T_{\text {iso }}$ and typical melting curves of synthetized samples are shown in Fig. 5. In
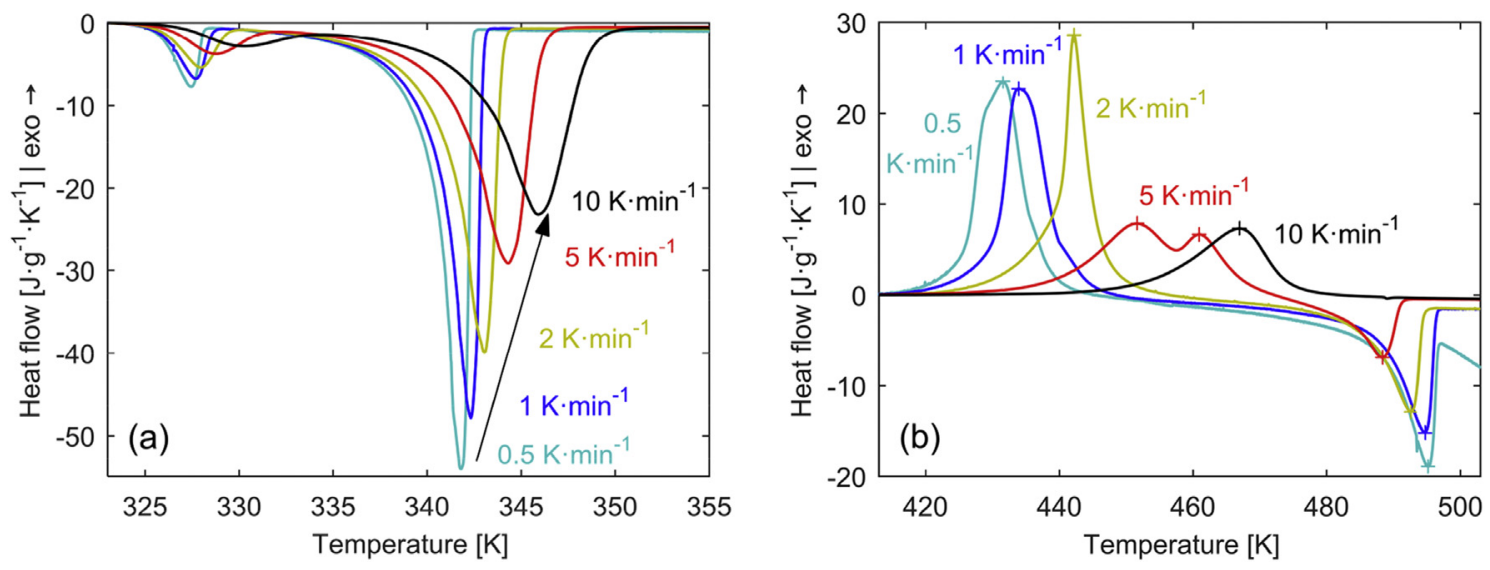

Fig. 1. DSC curves of non-isothermal syntheses of PA6 at different heating rates, (a) reactive mixture melting temperature range, (b) PA6 polymerization, crystallization and melting temperature range. 

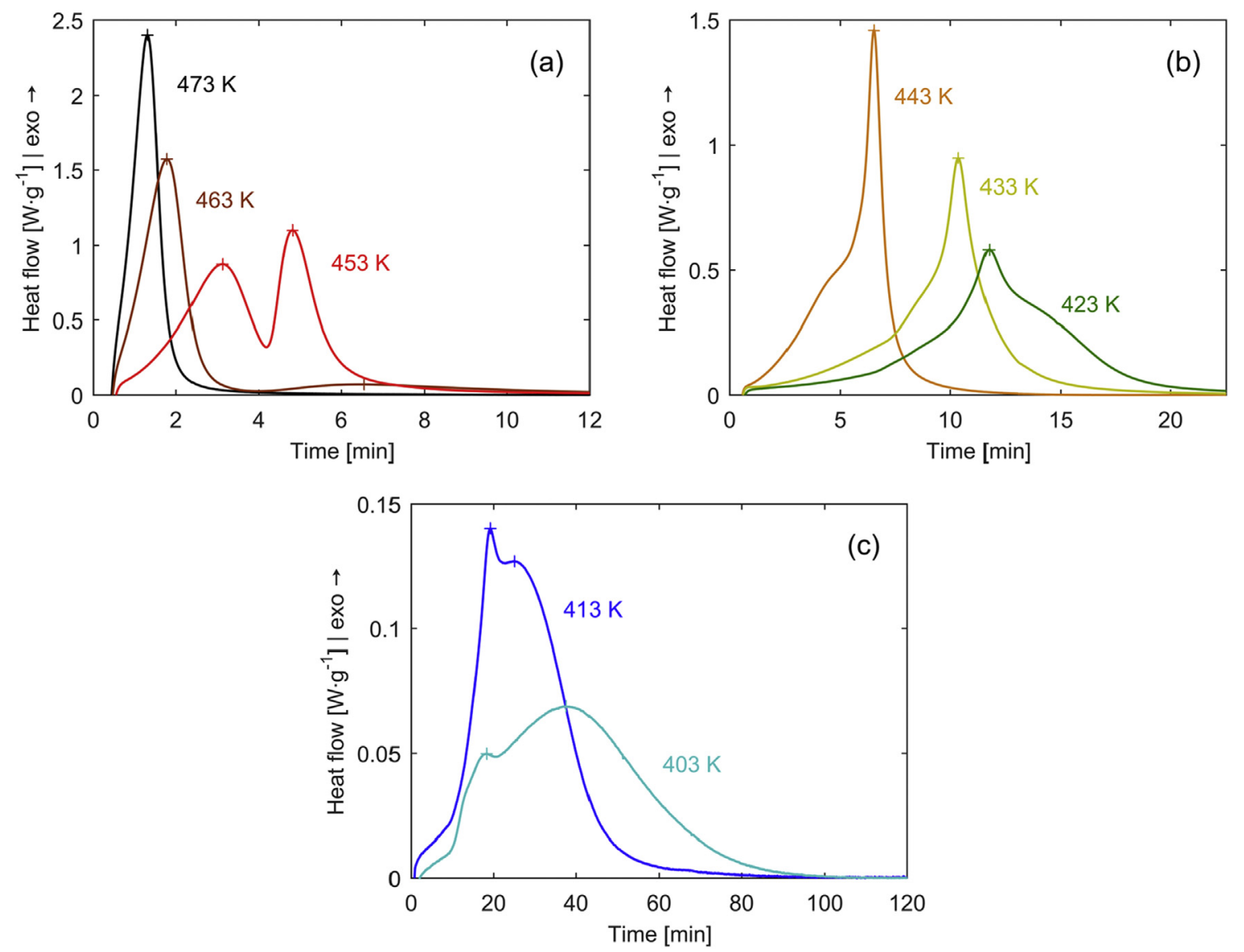

Fig. 3. DSC curves of isothermal syntheses of PA6, (a) for 453-463-473 K, (b) for 423-433-443 K and (c) for 403-413 K.

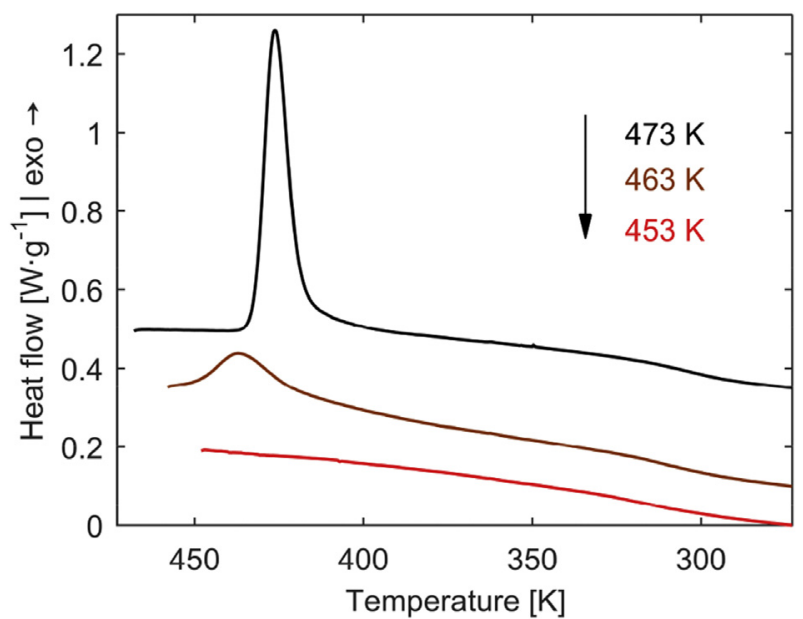

Fig. 4. DSC scans of the cooling step subsequent to isothermal syntheses of PA6.

Fig. 5, the melting curve of sample synthetized at $423 \mathrm{~K}$ is representative of all PA6 samples synthetized between 403 and $463 \mathrm{~K}$ and differs from the curve obtained for $T_{\text {iso }}=473 \mathrm{~K}$ by the position and the shape of the melting peak.

Even if all polymers melt during this last heating scan, the exothermic peaks on curves in Fig. 4 indicate that the crystalline structure was not systematically formed during the isothermal stage. In particular for a $T_{i s o}$ of $473 \mathrm{~K}$, the sharp crystallization peak and the distinct baseline above the peak show that PA6

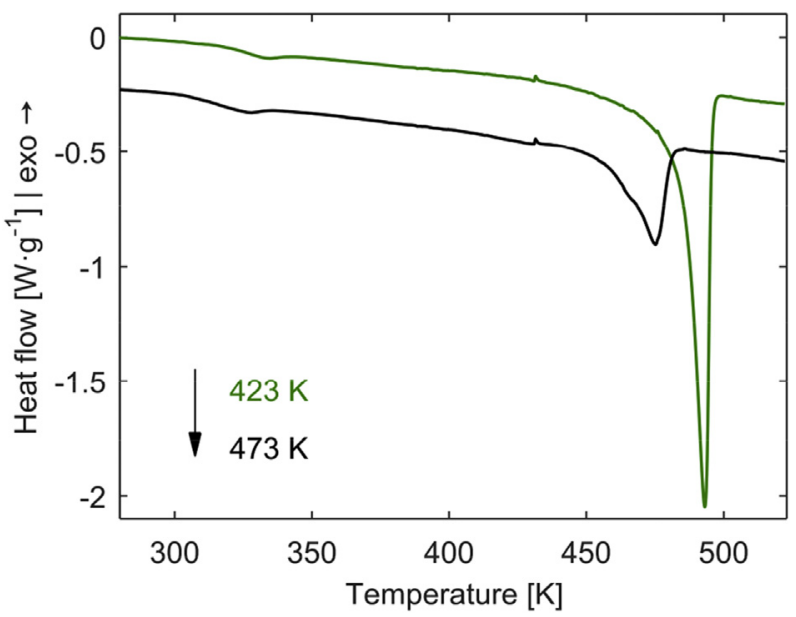

Fig. 5. Melting curves on heating scans of samples synthesized at $423 \mathrm{~K}$ and $473 \mathrm{~K}$.

crystallization only occurred during the cooling step. The single exothermic peak observed during syntheses at $473 \mathrm{~K}$ then corresponds to the polymerization solely and the synthesized PA6 polymer remained in liquid state. It is similar in that sense to the non-isothermal synthesis at $10 \mathrm{~K} \mathrm{~min}^{-1}$ (Fig. 1a).

After synthesis at $463 \mathrm{~K}$, a smaller crystallization peak starts at the beginning of the cooling phase (Fig. 4). This crystallization is partial as two distinct peaks appear on the DSC curves of the isothermal stage among which one is necessarily due to 
crystallization. The peak during the cooling stage therefore corresponds to a secondary crystallization process that completes the crystalline structure formed during the isothermal synthesis.

For lower temperatures, i.e. between 403 and $453 \mathrm{~K}$, no exothermic peak appears during cooling, meaning that the crystallization is achieved during the isothermal stage.

The shoulders and multiple peaks on reaction curves in Fig. 3 can reasonably be attributed to polymerization or crystallization. For clarity the time of apparition of each peak and the duration of the synthesis reaction are plotted in Fig. 6.

At $453 \mathrm{~K}$ and $463 \mathrm{~K}$ (Fig. 3a), the two exothermic peaks are clearly separated, similarly to the non-isothermal synthesis at $5 \mathrm{~K} \mathrm{~min}^{-1}$. The first peak is related to polymerization and the second one to crystallization, as polymerization represents a necessary condition for crystallization. Between 423 and $443 \mathrm{~K}$, the competition between phenomena kinetics leads to a main peak with a shoulder, each one resulting from polymerization or crystallization. In this range of temperature, synthesis is achieved in 15 min which represents a minimum synthesis time apart from the condition $T_{\text {iso }}=473 \mathrm{~K}$.

In the range from $423 \mathrm{~K}$ to $473 \mathrm{~K}$, the position of each peak confirms that the polymerization time decreases when increasing the synthesis temperature, like conventional thermoset resins [31] and that the temperature has an opposite effect on the crystallization kinetics between $453 \mathrm{~K}$ and $463 \mathrm{~K}$. As reported in literature on conventional PA6, the crystallization kinetic is actually controlled by the degree of supercooling in this range of temperature and the acceleration of the crystallization kinetic is expected until 403-423 $\mathrm{K}$ when decreasing the isotherm temperature [32,33]. Beyond this range, crystallization kinetic is strongly affected by molecular mobility and decreases when approaching the glass transition temperature.

At $403 \mathrm{~K}$ and $413 \mathrm{~K}$, because of these opposite temperature dependences, the slow polymerization competes with the instantaneous crystallization of polymer chains. However, only polymerized chains can crystallize and therefore the continuous increase of the total reaction time below $443 \mathrm{~K}$ is necessarily related to the temperature dependence of polymerization. The second exothermic peak on curves recorded at $403 \mathrm{~K}$ and $413 \mathrm{~K}$ (Fig. 3c) is thus related to polymerization and the first peak is due to the crystallization process. However crystallization cannot be only characterized by this small peak in the first minutes of the reaction, i.e. before polymerization is completed. It necessarily continues

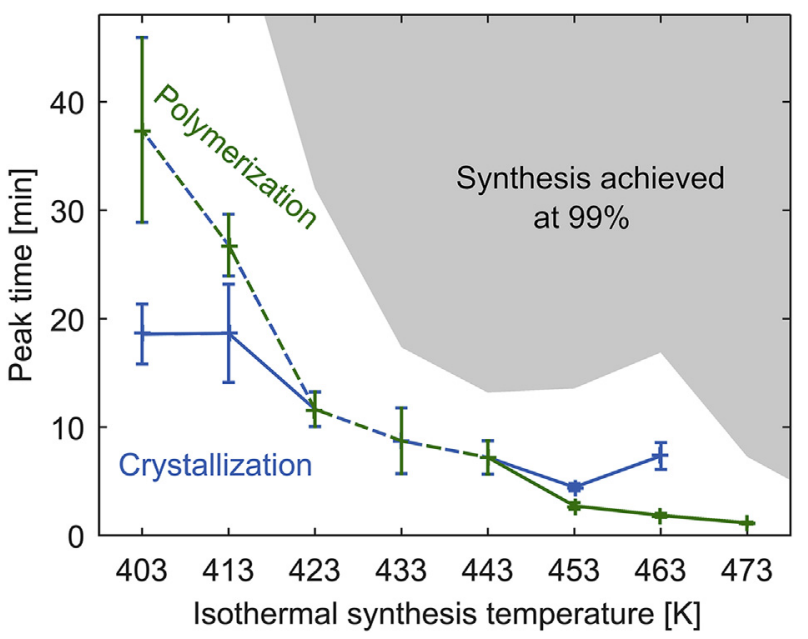

Fig. 6. Polymerization and crystallization times as a function of isothermal synthesis temperature. until the end of polymerization. Therefore crystallization is very probably a two-step process at low temperature. Nevertheless, the continuous increase in the maximum peak time of polymerization (Fig. 6) does not show a distinct influence of the crystallization on the polymerization kinetic.

\subsection{Total heat of synthesis reaction}

The total heat $Q_{\text {tot }}$ determined on DSC curves of isothermally and non-isothermally synthesized samples are summarized in Table 1 . The values of heat include polymerization and crystallization contributions even when two distinct peaks were observed.

The lowest values of $Q_{t o t}$ are obtained during syntheses at $\dot{T}=10 \mathrm{~K} \mathrm{~min}^{-1}$ and at $T_{\text {iso }}=473 \mathrm{~K}$. These conditions correspond to cases for which only one single polymerization peak was observed. The values of heat measured for these synthesis conditions are in good agreement with the total enthalpy of polymerization reported in literature that is comprised between 129.6 and $147.0 \mathrm{~J} \mathrm{~g}^{-1}$ depending on the reference used $[13,34,35]$.

For the lowest temperatures and heating rates, crystallization gives rise to a significant increase of $Q_{\text {tot }}$. The highest values are recorded for synthesis at $0.5 \mathrm{~K} \mathrm{~min}^{-1}$ and at $423 \mathrm{~K}$. However, it must be noticed that some variability was obtained at low temperature and low heating rate. It can be then assumed that the reaction globally leads to a high heat of reaction for any isotherm temperature and heating rate lower than $423 \mathrm{~K}$ and $1 \mathrm{~K} \mathrm{~min}^{-1}$ respectively.

In order to separate the contributions of polymerization and crystallization on the total heat of synthesis, TGA and DSC techniques were used to assess the final degree of polymerization and degree of crystallinity of the samples.

\subsection{Degree of conversion}

The final degree of conversion $X_{p}^{\infty}$ was determined from the residual amount of $\varepsilon$-caprolactam in DSC samples. Fig. 7 shows the TGA curves (the mass loss, the derivative of mass loss and the heat flow signal) recorded during a heating ramp at $5 \mathrm{~K} \mathrm{~min}^{-1}$ of a sample synthesized at $2 \mathrm{~K} \mathrm{~min}^{-1}$, which are representatives of all samples. The results indicate that the sample is almost fully degraded at $773 \mathrm{~K}$ with more than $99 \mathrm{wt} \%$ of mass loss.

Two distinctive ranges of mass loss are observable on TGA curves. The first range between 373 and $498 \mathrm{~K}$ corresponds to $\varepsilon$-caprolactam evaporation $[8,10,27,29,30]$ and eventually to water evaporation, although its amount should be negligible as the samples were stored in a desiccator prior to analysis. Monomer evaporation occurs simultaneously with the fusion of PA6, as revealed by the endothermic peak between 473 and $493 \mathrm{~K}$ on the heat flow curve. The second range of mass loss refers to the degradation of PA6, which starts around $573 \mathrm{~K}$ at $5 \mathrm{~K} \mathrm{~min}^{-1}$, as reported for commercial PA6 [36]. It induces a drop of the heat flow signal beyond $523 \mathrm{~K}$, as it was observed on the DSC scan of the sample synthesized at $0.5 \mathrm{~K} \mathrm{~min}^{-1}$ (Fig. 1b).

In order to define the residual monomer ratio, the derivative of the mass loss was used to identify the inflexion point between monomer evaporation and polymer degradation in the range of $518-533 \mathrm{~K}$. The transition is however not abrupt as monomer evaporation may occur beyond the selected point as well as polymer degradation may start before this limit (in particular oligomers) [30]. The final mass degrees of conversion $X_{p}^{\infty}$, as calculated using the ratio of residual mass $m_{\varepsilon-C L}$ of $\varepsilon$-caprolactam to the total mass of sample $m_{0}$ according to equation (1), then necessarily include some uncertainty. Nevertheless, values for isothermally and non-isothermally synthesized samples reported in Table 1 exhibit a reasonable standard deviation that allow comparing $X_{p}^{\infty}$ 
Table 1

Total heat of reaction, melting and crystallization enthalpies and degree of conversion of synthesized PA6 samples.

\begin{tabular}{|c|c|c|c|c|c|c|c|}
\hline & & Total heat of reaction & Melting temperature & Melting enthalpy & $\begin{array}{l}\text { Degree of conversion } \\
\text { (Eq. (1)) }\end{array}$ & $\begin{array}{l}\text { Crystallization enthalpy } \\
\text { (Eq. (4)) }\end{array}$ & $\begin{array}{l}\text { Melting enthalpy of } \\
\text { PA6 (Eq. (3)) }\end{array}$ \\
\hline & & $Q_{\text {tot }}\left[\mathrm{J} \mathrm{g}^{-1}\right]$ & $T_{m}[\mathrm{~K}]$ & $\Delta H_{m}\left[\mathrm{~J} \mathrm{~g}^{-1}\right]$ & $X_{p}^{\infty}[\mathrm{wt} . \%]$ & $\Delta H_{c}^{s u b}\left[\mathrm{~J} \mathrm{~g}^{-1}\right]$ & $\Delta H_{m}^{P A 6}\left[\mathrm{~J} \mathrm{~g}^{-1}\right]$ \\
\hline$\dot{T}\left[\mathrm{~K} \mathrm{~min}^{-1}\right]$ & $\begin{array}{l}0.5 \\
1 \\
2 \\
5 \\
10\end{array}$ & $\begin{array}{l}221.3 \pm 13.9 \\
213.5 \pm 2.2 \\
200.1 \pm 10.5 \\
161.0 \\
116.9 \pm 1.4\end{array}$ & $\begin{array}{l}494.5 \pm 1.2 \\
494.8 \pm 0.4 \\
492.8 \pm 0.2 \\
488.5 \\
-\end{array}$ & $\begin{array}{l}>75.4 \pm 2.9 \\
93.4 \pm 4.5 \\
85.8 \pm 4.9 \\
46.1 \\
0\end{array}$ & $\begin{array}{l}93.3 \pm 0.4 \\
93.4 \pm 0.5 \\
93.5 \pm 0.4 \\
93.5 \pm 0.2 \\
92.9 \pm 0.3\end{array}$ & $\begin{array}{l}106.1 \pm 14.4 \\
98.2 \pm 4.6 \\
84.5 \pm 11.3 \\
45.3 \pm 4.0 \\
2.0 \pm 4.3\end{array}$ & $\begin{array}{l}>80.8 \pm 2.9 \\
100.0 \pm 4.5 \\
91.7 \pm 4.9 \\
49.2 \\
0\end{array}$ \\
\hline$T_{\text {iso }}[\mathrm{K}]$ & $\begin{array}{l}403 \\
413 \\
423 \\
433 \\
443 \\
453 \\
463 \\
473\end{array}$ & $\begin{array}{l}196.3 \pm 11.1 \\
205.6 \pm 14.5 \\
219.8 \pm 3.3 \\
211.9 \pm 1.8 \\
198.4 \pm 8.3 \\
194.7 \pm 6.3 \\
142.3 \pm 10.1 \\
121.7 \pm 4.5\end{array}$ & $\begin{array}{l}491.1 \\
492.1 \\
493.4 \\
491.7 \\
488.4 \\
488.4 \\
487.9 \\
475.4\end{array}$ & $\begin{array}{l}95.7 \\
100.0 \\
100.6 \\
93.0 \\
81.0 \\
72.8 \\
- \\
-\end{array}$ & $\begin{array}{l}91.8 \pm 0.1 \\
93.8 \pm 0.6 \\
94.3 \pm 1.2 \\
94.8 \pm 0.5 \\
94.9 \pm 1.1 \\
96.7 \pm 0.1 \\
95.8 \pm 0.6 \\
94.6 \pm 0.7\end{array}$ & $\begin{array}{l}82.8 \pm 11.8 \\
90.3 \pm 15.1 \\
102.3 \pm 5.2 \\
95.2 \pm 4.4 \\
80.3 \pm 9.2 \\
75.1 \pm 7.5 \\
24.0 \pm 10.9 \\
4.3 \pm 6.0\end{array}$ & $\begin{array}{l}104.2 \\
106.6 \\
106.7 \\
98.1 \\
85.4 \\
75.3 \\
- \\
-\end{array}$ \\
\hline
\end{tabular}

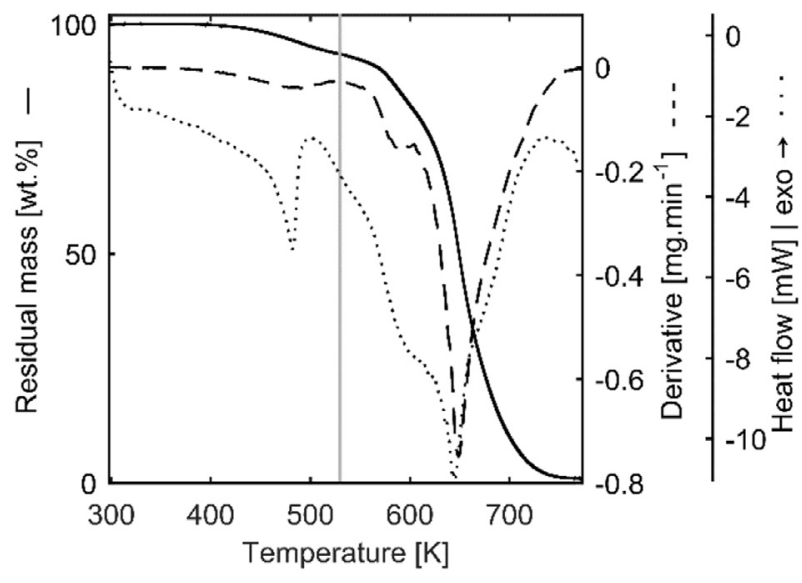

Fig. 7. TGA curve of a sample synthesized at $2 \mathrm{~K} \mathrm{~min}^{-1}$.

data.

$X_{p}^{\infty}=1-\frac{m_{\varepsilon-C L}}{m_{0}}$

An $X_{p}^{\infty}$ of about $93.3 \pm 0.3 \mathrm{wt} \%$ is reached after non-isothermal syntheses whatever the heating rate and $X_{p}^{\infty}$ varies from 91.8 to $96.7 \mathrm{wt} \%$ for isothermal syntheses. These ranges are in good agreement with the literature data $[6,8,30,37,38]$ and correspond to an almost complete conversion as the monomer-polymer equilibrium does not allow a $100 \mathrm{wt} \%$ conversion of $\varepsilon$-caprolactam [17,39].

The evolution of $X_{p}^{\infty}$ of isothermally synthetized samples seems to indicate that the degree of conversion first increases when increasing the synthesis temperature from 403 to $453 \mathrm{~K}$ and then decreases for higher temperatures. This last temperature corresponds to conditions for which polymerization and crystallization are decoupled. This effect on $X_{p}^{\infty}$ may thus be related to the level of coupling between polymerization and crystallization. Nevertheless, isothermal and non-isothermal syntheses lead to a high degree of conversion, which indicates that the differences in total synthesis enthalpies are essentially due to differences in the degree of crystallinity of the samples.

When only polymerization occurs during synthesis $\left(10 \mathrm{~K} \mathrm{~min}^{-1}\right.$ and $473 \mathrm{~K}$ ) or when polymerization and crystallization are completely decoupled ( $463 \mathrm{~K}$ ), the final degree of conversion gives access to the total enthalpy of polymerization $\Delta H_{p}^{100 \%}$ (Equation (2)).
$\Delta H_{p}^{100 \%}=\frac{\Delta H_{p}}{X_{p}^{\infty}}$

The $\Delta H_{p}^{100 \%}$ value calculated with equation (2) is equal to $123.5 \pm 4.1 \mathrm{~J} \mathrm{~g}^{-1}$, which is slightly lower than the literature range of $129.6-147.0 \mathrm{~J} \mathrm{~g}^{-1}[13,34,35]$.

\subsection{Enthalpies of crystallization and crystalline structure}

The quantification of crystalline phase formed during the synthesis reaction can be assessed from the enthalpy of fusion $\Delta H_{m}$ and from the enthalpy of crystallization $\Delta H_{c}^{\text {sub }}$, calculated by subtracting the part related to the polymerization from the total heat of synthesis $Q_{\text {tot }}$ using equation (3).

$\Delta H_{c}^{s u b}=Q_{t o t}-X_{p}^{\infty} \Delta H_{p}^{100 \%}$

$\Delta H_{m}$ and $\Delta H_{c}^{s u b}$ of isothermally and non-isothermally synthesized samples are presented in Table 1. $\Delta H_{m}$ obtained on samples cured at $463 \mathrm{~K}$ and $473 \mathrm{~K}$ were removed as crystallization was not fully achieved during the synthesis stage. As it can be observed in Table $1, \Delta H_{c}^{\text {sub }}$ values are in good agreement with $\Delta H_{m}$ data, showing DSC and TGA analysis are consistent. Only the enthalpy of fusion $\Delta H_{m}$ obtained at $\dot{T}=0.5 \mathrm{~K} \mathrm{~min}^{-1}$ is significantly lower than the related $\Delta H_{c}^{\text {sub }}$ because of the degradation that affects the DSC baseline (Fig. 1b).

The enthalpy recorded during non-isothermal syntheses rapidly decreases with increasing the heating rate. At the extreme, the application of high heating rates $\left(>10 \mathrm{~K} \mathrm{~min}^{-1}\right)$ prevents crystallization because of the late chain polymerization that is shifted towards high temperatures. A similar trend is observed with isothermally polymerized samples when the synthesis temperature is increased. Above $433 \mathrm{~K}$, the low supercooling limits progressively the ability of PA6 to crystallize. The synthesis conditions then strongly affect the crystallinity of polymerized PA6.

Moreover, as already reported by Liberti et al. [40], the enthalpies of fusion $\Delta H_{m}$ or crystallization $\Delta H_{c}^{\text {sub }}$ resulting from heating rates lower than $2 \mathrm{~K} \mathrm{~min}^{-1}$ and isothermal temperatures below $433 \mathrm{~K}$ are particularly high compared to conventional neat PA6 $[33,41]$. Such high enthalpies of melting were only observed when crystallization is achieved under high pressure $\left(>10^{8} \mathrm{~Pa}\right)[42]$. Kolesov et al. [33], who analyzed the influence of cooling rate on crystallization of PA6, actually concluded that extrapolation to zero cooling rate yields an enthalpy of crystallization of about $85 \mathrm{~J} \mathrm{~g}^{-1}$, which is significantly lower than the recorded values. These 
synthesis conditions (i.e. $\dot{T}<2 \mathrm{~K} \mathrm{~min}^{-1}$ and $T_{\text {iso }}<433 \mathrm{~K}$ ) correspond to slow polymerization kinetic for which crystallization is strongly coupled. This is even more significant when the final degree of conversion is taken into account. Indeed $\Delta H_{m}$ and $\Delta H_{c}^{s u b}$ represent the heat absorbed during the phase transition for each gram of initial mixture. The final degree of polymerization $X_{p}^{\infty}$ can be used to correct the enthalpy of crystallization since a part of the sample is remained in monomer form. The enthalpy of fusion $\Delta H_{m}^{P A 6}$ in Joule per gram of PA6 is obtained with equation (4) (Table 1).

$\Delta H_{m}^{P A 6}=\frac{\Delta H_{m}}{X_{p}^{\infty}}$

The crystalline structure of isothermally synthesized samples has been characterized by WAXS (Fig. 8). Non-isothermally synthetized samples were not characterized by WAXS since the crystalline phase formed was systematically melted during synthesis experiments. On Fig. 8, two main peaks emerge beyond the amorphous halo on the diffraction patterns whatever the reaction conditions, as well as a small inflection at around $21.5^{\circ}$. Comparatively, the higher peaks are obtained for $T_{\text {iso }}$ between 403 and $423 \mathrm{~K}$, which is in good agreement with DSC results regarding the degree of crystallinity.

The peaks at $2 \theta=20^{\circ}$ and $2 \theta=24^{\circ}$ correspond respectively to the diffraction planes (200) and (002)-(202) of the thermodynamically stable $\alpha$-type crystalline structure [43]. This phase is generally connected with the formation of high-order superstructures, like spherulites, and ensures high mechanical properties [44]. On the other hand, the inflection at around $21.5^{\circ}$ on diffraction patterns in Fig. 8 can be related to the presence of the mesomorphic $\gamma$-type crystalline structure in low proportion $[12,45]$. This $\gamma$ structure is thermodynamically less stable than the $\alpha$ structure and is only formed in conventional PA6: (i) under high cooling rates from the melt $\left(\dot{T}>20 \mathrm{~K} \mathrm{~s}^{-1}\right.$ ) [46,47], (ii) under isothermal crystallization from the melt at $T_{\text {iso }}<433 \mathrm{~K}$ [48], (iii) through annealing/ cold-crystallization of an amorphous sample below $433 \mathrm{~K}[41,45]$. Nevertheless, because of its unstable nature, the $\gamma$-type crystals aim to transform into more stable $\alpha$-type crystals when possible, i.e. when thermal conditions are favorable.

The low proportion of $\gamma$ phase in samples synthesized at $T_{i s o}<$

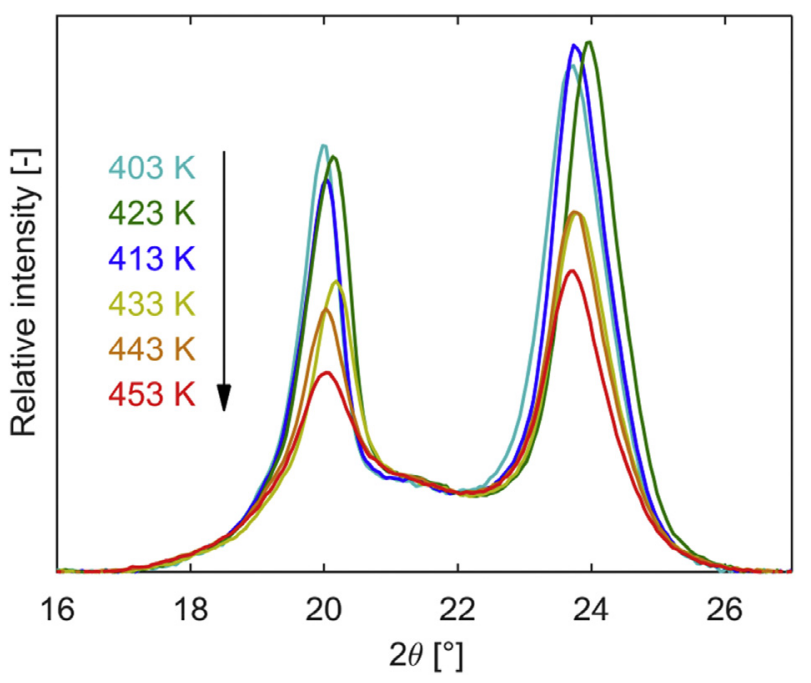

Fig. 8. WAXS scans of isothermally synthesized samples.
$433 \mathrm{~K}$ demonstrates that the polymerizing environment is favorable for the crystallization of PA6 chains. Therefore a low synthesis temperature not only allows to reach a high degree of crystallization but also inhibits the formation of the unstable $\gamma$ phase.

The presence of a single crystalline phase in all synthetized PA6 allows calculating the lamellar thickness distribution of PA6 crystallites using the approach proposed by Alberola et al. [49]. As demonstrated by Zhou et al. [50], this approach, based on the melting curves, allows obtaining lamellar distributions that are comparable to the ones determined by small-angle X-ray scattering or transmission electron microscopy. The distribution given by equation (5) is based on Gibbs-Thomson equation and is obtained considering that each crystal melts for a specific temperature depending on its thickness, which proportion is given by the heat flow recorded by DSC.

$\frac{1}{M_{c}} \frac{\mathrm{d} M_{c}}{\mathrm{~d} l_{c}}=\frac{\rho_{c} \phi\left(T_{m}^{0}-T\right)^{2}}{2 \sigma T_{m}^{0} \dot{T} X_{c}}$

In equation (5), $l_{c}$ refers to the lamellar thickness, $M_{c}$ and $\rho_{c}$ $\left(1.23 \mathrm{~g} \mathrm{~cm}^{-3}\right)$ are the mass and the density of the crystalline phase respectively, $\phi$ is the heat flow recorded during melting $\left(\mathrm{W} \mathrm{g}^{-1}\right), T_{m}^{0}$ is the equilibrium melting temperature of an infinite crystal (533 K) and $\sigma$ is the surface free energy per unit area of the basal face $\left(80.10^{-3} \mathrm{~J} \mathrm{~m}^{-2}[51]\right)$.

Fig. 9 shows the lamellar thickness distribution of isothermally and non-isothermally synthesized PA6 calculated with equation (5). The lamellar distribution of samples synthetized under nonisothermal conditions at low rates is characterized by a thick crystalline structure with a narrow distribution, while the $5 \mathrm{~K} \mathrm{~min}^{-1}$ condition led to a thinner lamellar morphology. This different lamellae size obtained during synthesis at $5 \mathrm{~K} \mathrm{~min}^{-1}$ can result from the different crystallization kinetic at this rate, as crystallization occurs after polymerization is almost achieved (decoupling) or to the different range of crystallization temperature. The calculation of the lamellar distribution is however sensitive to heating rate as at low heating rates PA6 is subjected to annealing and at higher heating rates, the morphology is better preserved but the effect of thermal lag is more pronounced. Since the melting peaks have been obtained at different heating rate, the determined distribution curves may thus not truly represent the original morphology in particular regarding the distribution broadness.

On the contrary, the lamellar distribution of samples synthetized under isothermal conditions are determined from melting peaks obtained during the subsequent heating cycle at $10 \mathrm{~K} \mathrm{~min}^{-1}$. Therefore the distribution curves are reliable and can be directly compared. Moreover this heating rate represents a suitable condition which provides distribution data similar to SAXS according to Zhou et al. [50]. The broader distribution of isothermal samples (Fig. 9b) actually demonstrates that annealing was limited during the heating stage. As shown in Fig. 9b, a thick lamellar morphology of about $7 \mathrm{~nm}$ is formed during isothermal synthesis below $463 \mathrm{~K}$. Only the lamellar distribution resulting from the isothermal condition $T_{\text {iso }}=473 \mathrm{~K}$ differs from the other temperatures as this condition led to the formation of a thinner crystalline morphology. At this synthesis temperature, the crystallization occurred during the following cooling step at $-10 \mathrm{~K} \mathrm{~min}^{-1}$, the resulting crystalline microstructure is thus representative of the lamellae size of a conventional polymer of similar molecular weight. These distribution data then demonstrate that crystallization of PA6 chains is favored when it occurs during polymerization and systematically 

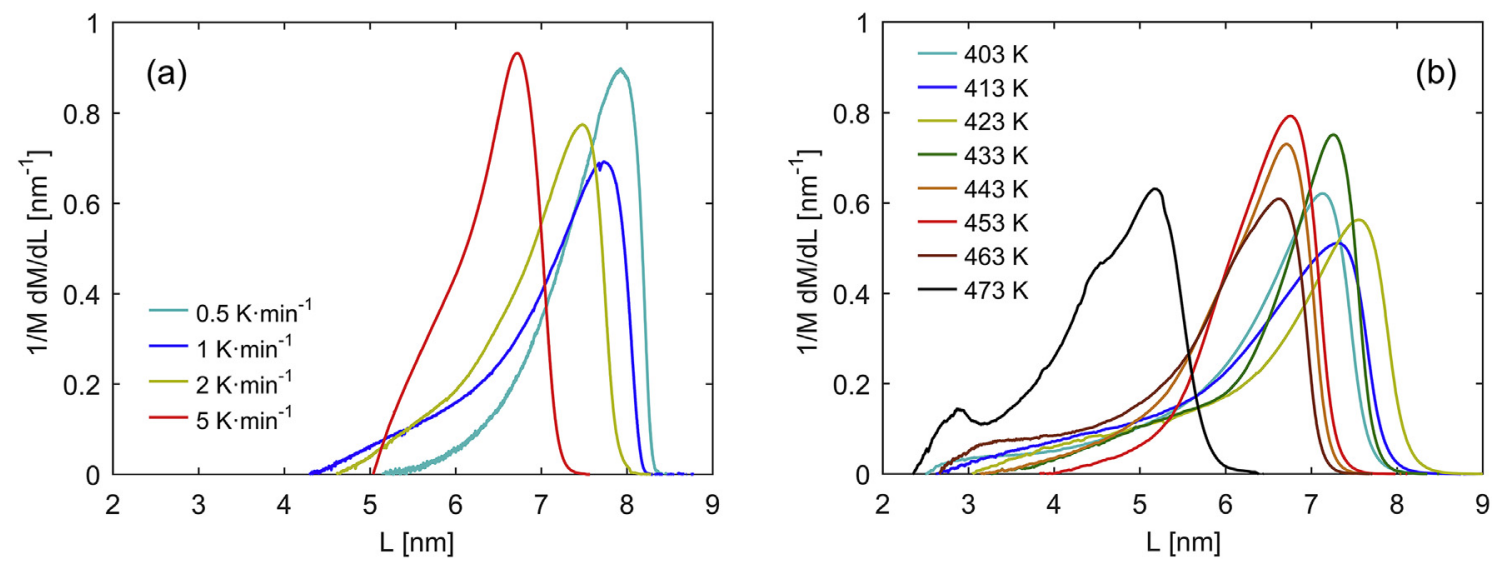

Fig. 9. Lamellar thickness distribution of PA6 crystalline phase, (a) for non-isothermal syntheses, (b) for isothermal syntheses.

results in a thicker lamellar morphology.

\subsection{Discussion}

The variation of the final degree of conversion and the properties of the crystalline phase with synthesis conditions confirms the influence of the coupling level between polymerization and crystallization. However, this interaction cannot be restricted to a simple kinetic competition between crystallization and polymerization. The two-step crystallization process that is observed for the lowest synthesis temperatures indeed demonstrates that both phenomena interfere with each other and that the interaction between polymerization and crystallization is temperature dependent.

At low isothermal temperature, the polymerization is slow and the concentration of monomer in the reactive mixture remains high for a long period of time. In this reactive environment, the crystallization kinetic is not limited by the degree of supercooling but by the molecular weight of polymer chains that slowly increases. The overall crystallization kinetic is thus mainly controlled by the instantaneous crystallization of chains portions as they are polymerized, and both crystallization and polymerization exhibit similar kinetics.

The apparition of a small but sudden crystallization peak on DSC curves at 403 and $413 \mathrm{~K}$ reveals that a second interaction occurs at the early stage of the synthesis reaction, when the reactive mixture consists in oligomers dispersed in a monomer phase. In fact the nucleation process that initiates crystallization, i.e. the formation of critical stable nuclei, requires a minimal chain length in order to fold [39,52-54] or a minimal concentration of oligomers [39,55]. Therefore nucleation cannot occur from the very start of the polymerization and according to Fig. $3 \mathrm{c}$ would take about $10 \mathrm{~min}$ to be formed. The small peak then would result from the instantaneous crystallization of available chains once nucleation becomes possible.

Moreover this sudden crystallization process at low temperature most certainly requires the aggregation of oligomers in the reactive system before crystallization. The concentration of oligomers is actually one mechanism that can induce nucleation [39,55]. The apparition of the intense crystallization peak at low temperature then would be consistent with the observation of some authors, who noticed a change of the initially homogeneous mixture into a heterogeneous cloudy system [56-59]. The driving forces of this possible liquid-liquid phase separation at the beginning of the synthesis reaction could be attributed to the formation of hydrogen bonding.
The particular crystallization during synthesis at low temperatures leads to a high enthalpy of crystallization and to a thick lamellar morphology that is a consequence of a better chain mobility in the reactive mixture environment, compared to the chain mobility in a conventional PA6 at the molten state. Indeed, these results cannot be attributed to a particular molecular weight or architecture of synthetized PA6 molecules, since crystallization occurs during polymerization. The high concentration of monomer in the reactive mixture is most probably one of the reasons for this mobility. It reduces the viscosity of the system and thus improves chain diffusion as well as chain disentanglement. The fact that crystallization involves polymer molecules with a lower molecular weight than the final one is also a possible cause of the improvement of the crystalline morphology at low temperature. Several authors indeed showed for instance that the spherulite growth rate decreases with increasing the molecular weight as this parameter also affects chain mobility [60-65].

By reducing the level of coupling when increasing the synthesis temperature, the chain mobility decreases because the degree of supercooling is lower and the degree of conversion and the molecular weight of synthetized molecules are both advanced when crystallization starts. At the extreme, when the synthesis conditions induce a fully decoupled reaction, then the crystallization is equivalent to the crystallization of conventional polymers from the melt, which explain the lower crystallinity and lamellar morphology obtained for $T_{\text {iso }}=453 \mathrm{~K}$.

The evolution of the crystalline structure with the synthesis conditions and in particular with the level of coupling between both phenomena shows that the polymerization strongly affects the crystallization. The reciprocal is however also probable according to the evolution of the final degree of conversion $X_{p}^{\infty}$ of isothermally synthetized samples. Indeed, several authors $[21,39,57,66]$ mentioned a possible slowdown of the polymerization at low temperature, i.e. in conditions of high supercooling and fast crystallization kinetic. This could be a consequence of the entrapment of reactive species inside the crystalline structure during its formation, reducing the availability of active centers and the degree of conversion. Isothermal kinetic results however did not show evidence of some particular change of polymerization kinetic trend with the synthesis temperature, except the conventional temperature dependence of a chemical reaction. Nevertheless, such entrapment mechanism could explain the decrease of $X_{p}^{\infty}$ with synthesis temperature, as temperature controls the level of coupling and the crystallization kinetic.

According to this assumption, the degree of conversion should stabilize to a constant value from the moment polymerization and 
crystallization are decoupled but the results in Table 1 show a decrease above $453 \mathrm{~K}$. This temperature represents a transition at which unwanted side reactions may appear. Anionic polymerization of $\varepsilon$-caprolactam into PA6 is indeed particular in that it has no radical termination. Side reactions may then occur at high temperature like branching or depolymerization [67]. The constant $X_{p}^{\infty}$ values of non-isothermal samples, which were all heated up to $523 \mathrm{~K}$, would indicates that a similar reaction equilibrium could be reached at the end of the reaction after melting whatever the heating rate. The value of $X_{p}^{\infty}$ would thus depends on the maximum temperature applied to the material.

\section{Conclusion}

The synthesis of PA6 from a reactive mixture of $\varepsilon$-caprolactam designed for thermoplastic composite manufacturing was characterized under isothermal and non-isothermal conditions using DSC technique. Contrary to an adiabatic reactor that averages the kinetics of phenomena, DSC technique allowed to highlight the specific contributions of polymerization and crystallization over a wide range of temperatures and heating rates. The DSC results then give new insight on the temperature dependent coupling between polymerization and crystallization.

When polymerization is achieved at high temperature, i.e. during an isotherm stage above $473 \mathrm{~K}$ or during a heating step at $10 \mathrm{~K} \mathrm{~min}^{-1}$ and over, the low supercooling prevents crystallization to occur. Synthesis of PA6 then only depends on polymerization kinetic that is all the more rapid that the temperature is high. Side reactions may however be activated at high temperature and may affect the final degree of conversion. Moreover, when the polymer is synthetized at high temperature, crystallization occurs during cooling and final properties are therefore similar to a conventional PA6 (crystallinity and lamellar morphology).

Because of the opposite temperature dependency of both phenomena, the reduction of the synthesis temperature or heating rate slows down the polymerization kinetic while favoring crystallization. At early stage of the reaction, the synthesis kinetics corresponds to the polymerization kinetics and then continues with the crystallization. This decoupling is due to the significant difference of kinetics in the range of temperature from 453 to $463 \mathrm{~K}$. A similar decoupled behavior is observed for a heating rate of about $5 \mathrm{~K} \mathrm{~min}^{-1}$.

Crystallization strongly interacts with polymerization for higher supercooling, below $433 \mathrm{~K}$ or below $2 \mathrm{~K} \mathrm{~min}^{-1}$. When PA6 synthesis is achieved in these conditions, crystallization can start at the early stages of the polymerization. Crystallization kinetic then strongly depends on the kinetic of chain extension and polymerization controls the overall synthesis time. The DSC curves obtained at low temperature exhibit in addition a crystallization peak in the first minutes of the reaction. This would be due to a critical molecular weight that is required for nucleation to occur. Moreover the reactive system environment favors chain mobility, which allows forming a large amount of thick lamellae. The strongly coupled phenomena at low temperature may also affect the degree of conversion of the synthetized polymer and the entrapment of reactive species in the crystal structure could be the cause of the observed differences.

Among the isothermal conditions, $T_{\text {iso }}=423-433 \mathrm{~K}$ represent an interesting compromise of lamellar size, degree of crystallinity and degree of conversion, while providing a reasonable synthesis time compatible with composite manufacturing.

In order to confirm the previous conclusions, the evolution of the molecular weight, chains architecture and molecular weight distribution should be characterized over time, as these data would provide a better understanding of PA6 synthesis and resulting properties. A global simulation of liquid reactive processes depending on thermal cycle is also required for the optimization of the manufacturing conditions of thermoplastic composites with reactive PA6 systems. This experimental database then could be used for kinetic modelling of phenomena in order to edit TimeTemperature-Transformation (TTT) diagrams.

\section{Acknowledgment}

Brüggemann Chemical, Germany are acknowledged for kindly supplying reactants.

\section{References}

[1] U.K. Vaidya, K.K. Chawla, Processing of fibre reinforced thermoplastic composites, Int. Mater. Rev. 53 (4) (2008) 185-218.

[2] K. van Rijswijk, H.E.N. Bersee, Reactive processing of textile fiber-reinforced thermoplastic composites - an overview, Compos. Part A Appl. Sci. Manuf. 38 (3) (2007) 666-681.

[3] S.V. Lomov, Non-crimp Fabric Composites: Manufacturing, Properties and Applications, Elsevier, 2011.

[4] E. Bessard, Matériaux composites structuraux à base PEEK élaborés par thermo-compression dynamique : relation procédé-propriétés, 2012. PhD thesis.

[5] R. Brooks, Forming Technology for Thermoplastic Composites, Elsevier, 2014.

[6] K. van Rijswijk, Thermoplastic Composite Wind Turbine Blades - Vacuum Infusion Technology for Anionic Polyamide-6 Composites, Technische Universiteit Delft, 2007. Theses.

[7] R.S. Davé, R.L. Kruse, K. Udipi, D.E. Williams, Polyamides from lactams via anionic ring-opening polymerization: 3. rheology, Polymer 38 (4) (1997) 949-954.

[8] G. Van Den Broek D'Obrenan, The Adaptation of the RTM (Resin Transfer Molding) Process to Manufacture Thermoplastic-based Composites, INSA de Lyon, 2011. Theses.

[9] L. Zingraff, V. Michaud, P.-E. Bourban, J.-A.E. Manson, Resin transfer moulding of anionically polymerised polyamide 12, Compos. Part A Appl. Sci. Manuf. 36 (12) (2005) 1675-1686.

[10] Y. Gong, A. Liu, G. Yang, Polyamide single polymer composites prepared via in situ anionic polymerization of e-caprolactam, Compos. Part A Appl. Sci. Manuf. 41 (8) (2010) 1006-1011.

[11] K. van Rijswijk, H.E.N. Bersee, A. Beukers, S.J. Picken, A.A. van Geenen, Optimisation of anionic polyamide- 6 for vacuum infusion of thermoplastic composites: influence of polymerisation temperature on matrix properties, Polym. Test. 25 (3) (2006) 392-404.

[12] N. Dencheva, Z. Denchev, A.S. Pouzada, A.S. Sampaio, A.M. Rocha, Structureproperties relationship in single polymer composites based on polyamide-6 prepared by in-mold anionic polymerization, J. Mater. Sci. 48 (20) (2013) 7260-7273.

[13] S.A. Bolgov, V.P. Begishev, A.Ya Malkin, V.G. Frolov, Role of the functionality of activators during isothermal crystallization accompanying the activated anionic polymerization of $\varepsilon$-caprolactam, Polym. Sci. U.S.S.R. 23 (6) (1981) 1485-1492.

[14] K.J. Kim, D.S. Hong, A.R. Tripathy, Kinetics of adiabatic anionic copolymerization of $\varepsilon$-caprolactam in the presence of various activators, J. Appl. Polym. Sci. 66 (6) (1997) 1195-1207.

[15] J. Verrey, M.D. Wakeman, V. Michaud, J.-A.E. Månson, Manufacturing cost comparison of thermoplastic and thermoset rtm for an automotive floor pan, Compos. Part A Appl. Sci. Manuf. 37 (1) (2006) 9-22.

[16] P.W. Sibal, R.E. Camargo, C.W. Macosko, Designing nylon-6 polymerization systems for rim, Polym. Process Eng. 1 (2) (1984) 147-169.

[17] O. Wichterle, J. Sebenda, J. Kralicek, The anionic polymerization of caprolactam, Adv. Polym. Sci. $2 / 4$ (1961) 578-595.

[18] T.M. Frunze, R.B. Shleifman, E.M. Belavtseva, Ya V. Genin, T.V. Volkova, V.A. Kotel'nikov, L.G. Radchenko, S.P. Davtyan, V.V. Kuraschev, D. Ya. Tsvankin, Kinetic studies of structure formation during anionic adiabatic polymerization of e-caprolactam, J. Polym. Sci. Polym. Phys. Ed. 18 (7) (1980) 1523-1532.

[19] G.C. Alfonso, G. Bonta, S. Russo, A. Traverso, Adiabatic polymerization of ecaprolactam in presence of lithium chloride, 1. thermodynamic and kinetic aspects, Die Makromol. Chem. 182 (3) (1981) 929-939.

[20] S. Russo, A. Imperato, A. Mariani, F. Parodi, The fast activation of $\varepsilon$-caprolactam polymerization in quasi-adiabatic conditions, Macromol. Chem. Phys. 196 (10) (1995) 3297-3303.

[21] R.S. Davé, K. Udipi, R.L. Kruse, L.R. Stebbins, Polyamides from lactams via anionic ring-opening polymerization: 2. kinetics, Polymer 38 (4) (1997) 939-947.

[22] J. Teuwen, Thermoplastic Composite Wind Turbine Blades - Kinetics and Processability, Technische Universiteit Delft, 2011. PhD thesis.

[23] A. Rigo, G. Fabbri, G. Talamini, Kinetic study of anionic polymerization of 6caprolactam by differential calorimetry, J. Polym. Sci. Polym. Lett. Ed. 13 (8) (1975) 469-477. 
[24] J. Karger-Kocsis, L. Kiss, Dsc studies on the activated anionic polymerization of $\varepsilon$-caprolactam in the presence of crown compounds, J. Polym. Sci. Polym. Symposia 69 (1) (1981) 67-71.

[25] A.Ya Malkin, V.P. Beghishev, S.A. Bolgov, The exothermal effects of superimposed processes of activated anionic polymerization of $\varepsilon$-caprolactam and crystallization of the polymer formed, Polymer 23 (3) (1982) 385-390.

[26] D.L. Wilfong, C.A. Pommerening, Z.G. Gardlund, Separation of polymerization and crystallization processes for nylon-6, Polymer 33 (18) (1992) 3884-3888.

[27] K. Khodabakhshi, Anionic Polymerisation of Caprolactam: an Approach to Optimising the Polymerisation Conditions to Be Used in a Jetting Process, Loughborough University, 2011. PhD thesis.

[28] K. Ueda, K. Yamada, M. Nakai, T. Matsuda, M. Hosoda, K. Tai, Synthesis of high molecular weight nylon 6 by anionic polymerization of $\varepsilon$-caprolactam, Polym. J. 28 (5) (1996) 446-451.

[29] S. Pillay, U.K. Vaidya, G.M. Janowski, Liquid molding of carbon fabricreinforced nylon matrix composite laminates, J. Thermoplast. Compos. Mater. 18 (6) (2005) 509-527.

[30] C.-L. Zhang, L.-F. Feng, G.-H. Hu, Anionic polymerization of lactams: a comparative study on various methods of measuring the conversion of ع-caprolactam to polyamide 6, J. Appl. Polym. Sci. 101 (3) (2005) 1972-1981.

[31] C. Paris, Étude et modélisation de la polymérisation dynamique de composites à matrice thermodurcissable, Université de Toulouse, 2011. PhD thesis.

[32] J.H. Magill, Crystallization kinetics study of nylon 6, Polymer 3 (0) (1962) 655-664.

[33] I. Kolesov, D. Mileva, R. Androsch, C. Schick, Structure formation of polyamide 6 from the glassy state by fast scanning chip calorimetry, Polymer 52 (22) (2011) 5156-5165.

[34] Z. Bukac, P. Cefelin, D. Doskocilová, J. Šebenda, Alkaline polymerization of 6caprolactam, xviii. Equilib. between monomer Polym. 29 (1964) 2615.

[35] O. Wichterle, J. Tomka, J. Sebenda, Alkalische polymerisation des 6caprolactams xii. Über die polymerisation von 6-caprolactam und die kristallisation des gebildeten polymeren unter adiabatischen bedingungen, Collect. Czech. Chem. Commun. 29 (3) (1964) 610-624.

[36] K.P. Pramoda, Tianxi Liu, Zhehui Liu, Chaobin He, Hung-Jue Sue, Thermal degradation behavior of polyamide 6/clay nanocomposites, Polym. Degrad. Stab. 81 (1) (2003) 47-56.

[37] R.S. Davé, K. Udipi, R.L. Kruse, L.R. Stebbins, Polyamides from lactams via anionic ring-opening polymerization: 1 . chemistry and some recent findings, Polymer 38 (4) (1997) 927-938.

[38] L. Ricco, S. Russo, G. Orefice, F. Riva, Anionic poly(e-caprolactam): relationships among conditions of synthesis, chain regularity, reticular order, and polymorphism, Macromolecules 32 (23) (1999) 7726-7731.

[39] B. Wunderlich, Macromolecular Physics - Crystal Nucleation Growth Annealing vol. 2, Academic Press, 1976.

[40] F.N. Liberti, B. Wunderlich, Melting of polycaprolactam, J. Polym. Sci. Part A-2 Polym. Phys. 6 (5) (1968) 833-848.

[41] M. Kyotani, Studies on crystalline forms of nylon 6. III. crystallization from the glassy state, J. Macromol. Sci. Part B 11 (4) (1975) 509-525.

[42] S. Gogolewski, M. Gasiorek, K. Czerniawska, A.J. Pennings, Annealing of meltcrystallized nylon 6, Colloid Polym. Sci. 260 (9) (1982) 859-863.

[43] K.-H. Illers, Polymorphie, kristallinität und schmelzwärme von poly( $\varepsilon$-caprolactam), 2, Makr 179 (1978) 497-507.

[44] N.S. Murthy, V.A. Kagan, R.G. Bray, Effect of melt temperature and skin-core morphology on the mechanical performance of nylon 6, Polym. Eng. Sci. 42 (5) (2002) 940-950.

[45] I. Kolesov, R. Androsch, The rigid amorphous fraction of cold-crystallized polyamide 6, Polymer 53 (21) (2012) 4770-4777.

[46] V. Brucato, S. Piccarolo, V. La Carrubba, An experimental methodology to study polymer crystallization under processing conditions. the influence of high cooling rates, Chem. Eng. Sci. 57 (19) (2002) 4129-4143.

[47] D. Cavallo, L Gardella, G.C. Alfonso, G. Portale, L. Balzano, R. Androsch, Effect of cooling rate on the crystal/mesophase polymorphism of polyamide 6 , Colloid Polym. Sci. 289 (9) (2011) 1073-1079.

[48] M. Kyotani, S. Mitsuhashi, Studies on crystalline forms of nylon 6. ii. crystallization from the melt, J. Polym. Sci. Part A-2 Polym. Phys. 10 (8) (1972) 1497-1508.

[49] N. Alberola, J.Y. Cavaille, J. Perez, Mechanical spectrometry of alpha relaxations of high-density polyethylene, J. Polym. Sci. Part B Polym. Phys. 28 (4) (1990) 569-586.

[50] H. Zhou, G.L. Wilkes, Comparison of lamellar thickness and its distribution determined from d.s.c., saxs, tem and afm for high-density polyethylene films having a stacked lamellar morphology, Polymer 38 (23) (1997) 5735-5747.

[51] B. Wunderlich, Macromolecular Physics - Crystal Melting vol. 3, Academic Press, 1980

[52] V.V. Korshak, T.M. Frunze, S.P. Davtyan, VV. Kurashev, T.V. Volkova, V.A. Kot'elnikov, R.B. Shleifman, Kinetics of activated anionic polymerization of $\varepsilon$-caprolactam under non-isothermal conditions, Polym. Sci. U.S.S.R. 21 (9) (1979) 2161-2169.

[53] J.D. Hoffman, Theoretical aspects of polymer crystallization with chain folds: bulk polymers, Polym. Eng. Sci. 4 (4) (1964) 315-362.

[54] P.H. Lindenmeyer, Imperfections in polymer crystals, Kolloid-Zeitschrift Z. für Polym. 231 (1) (1969) 593-605.

[55] S.P. Davtyan, P.V. Zhirkov, S.A. Vol'fson, Problems of non-isothermal character in polymerisation processes, Russ. Chem. Rev. 53 (2) (1984) 150.

[56] G. Champetier, H. Sekiguchi, Mécanisme réactionnel de la polymérisation anionique des lactames, J. Polym. Sci. 48 (150) (1960) 309-319.

[57] T. Komoto, M. Iguchi, H. Kanetsuna, T. Kawai, Formation of spherulites during polymerization of lactams, Die Makromol. Chem. 135 (1) (1970) 145-164.

[58] A.Ya. Malkin, S.G. Kulichikhin, A.E. Chalykh, The effect of deformation on the phase separation in the polycapramide-caprolactam system, Polymer 22 (10) (1981) 1373-1376

[59] S. Russo, E. Casazza, Ring-opening Polymerization of Cyclic Amides (Lactams), in: K. Matyjaszewski, M. Moeller (Eds.), Polymer Science: a Comprehensive Reference, Volume 4, Chapter Chapter 14, Pages 331-396, Elsevier, 2012.

[60] J.H. Magill, Crystallization of poly-(tetramethyl-p-silphenylene)-siloxane polymers, J. Appl. Phys. 35 (11) (1964) 3249-3259.

[61] J.H. Magill, Crystallization of poly(tetramethyl-p-silphenylene)-siloxane (tmps) polymers. part ii, J. Polym. Sci. Part A-2 Polym. Phys. 5 (1) (1967) 89-99.

[62] F. Van Antwerpen, D.W. Van Krevelen, Influence of crystallization temperature, molecular weight, and additives on the crystallization kinetics of poly(ethylene terephthalate), J. Polym. Sci. Polym. Phys. Ed. 10 (12) (1972) 2423-2435.

[63] M. Gahleitner, K. Bernreitner, W. Neissl, C. Paulik, E. Ratajski, Influence of molecular structure on crystallization behaviour and mechanical properties of polypropylene, Polym. Test. 14 (2) (1995) 173-187.

[64] C. Duplay, B. Monasse, J.-M. Haudin, J.-L. Costa, Shear-induced crystallization of polypropylene: influence of molecular weight, J. Mater. Sci. 35 (24) (2000) 6093-6103.

[65] S. Umemoto, N. Okui, Power law and scaling for molecular weight dependence of crystal growth rate in polymeric materials, Polymer 46 (20) (2005) 8790-8795.

[66] K.H. Lee, S.C. Kim, Reaction-induced crystallization kinetics during the anionic polymerization of $\varepsilon$-caprolactam, Polym. Eng. Sci. 28 (1) (1988) 13-19.

[67] H.K. Reimschuessel, Nylon 6. chemistry and mechanisms, J. Polym. Sci. Macromol. Rev. 12 (1) (1977) 65-139. 